\title{
Modelling of gas permeation through ceramic coatings produced by thermal spraying
}

\author{
I.O. Golosnoy, S. Paul, T.W. Clyne* \\ Department of Materials Science and Metallurgy, Cambridge University, Pembroke Street, Cambridge CB2 3QZ, UK
}

Received 14 April 2007; received in revised form 26 August 2007; accepted 5 September 2007

\begin{abstract}
An analytical model has been developed for simulation of gas permeation through thermal spray coatings, and for prediction of the permeability. The model is based on a geometrical representation of the coating microstructure. This involves thin splats, with limited inter-splat bridging, and microcracks within the splats. Important variables include the thickness (smallest dimension) of the inter-splat pores and intra-splat microcracks. Uniform values of these parameters are used in the model. Predicted permeabilities are compared with experimental data obtained using plasma-sprayed zirconia coatings, both in the as-sprayed state and after heat treatments sufficient to generate significant microstructural changes via sintering effects. In general, good agreement is obtained and it is concluded that the model constitutes a useful tool for exploration of gas permeation characteristics in coatings or layers produced by thermal spraying.

(C) 2007 Acta Materialia Inc. Published by Elsevier Ltd. All rights reserved.
\end{abstract}

Keywords: Gas permeability; Analytical modelling; Plasma spray coatings; Porous material

\section{Introduction}

Thermal spray coatings are widely used for thermal and environmental protection [1-5]. It is known [6-8] that many such coatings, particularly zirconia thermal barrier coatings (TBCs), exhibit relatively high gas permeabilities and offer little resistance to the permeation of oxidizing gases under service conditions. In fact, diffusive oxygen transport through the lattice and via grain boundaries is also relatively rapid in these materials [8-10] and it is accepted that oxidation-resistant layers must be introduced if the substrate is to be protected from chemical attack by oxidizing species. In addition, there are various applications in which the pore architecture and fluid permeation characteristics of sprayed coatings are of critical importance. These include solid oxide fuel cells (SOFCs) [11-13], gas filters [14] and separators [15]. In some such applications, relatively high permeability is desirable, while

\footnotetext{
* Corresponding author.

E-mail address: twc10@cam.ac.uk (T.W. Clyne).
}

for others it needs to be kept within certain limits or minimized.

While understanding and control of gas permeation through sprayed coatings is thus of considerable technological importance, there have been relatively few experimental measurements $[6-8,16,17]$ of their permeability, and even fewer studies of how it changes under service conditions (particularly prolonged exposure to high temperature). This is a significant deficiency, since it is well established [18-22] that such exposure commonly leads to sintering phenomena which can radically change the coating microstructure (including the pore architecture) and strongly affect properties such as the stiffness [18,23-25] and the thermal conductivity [26-29]. Permeability might thus be expected to change during prolonged heat treatments.

Furthermore, theoretical treatment and modelling of gas permeation through the pore network in thermal spray coatings (or, indeed, in other types of coating) has hitherto been rather limited. While the background theory of gas flow through porous media is well established [30-32], 


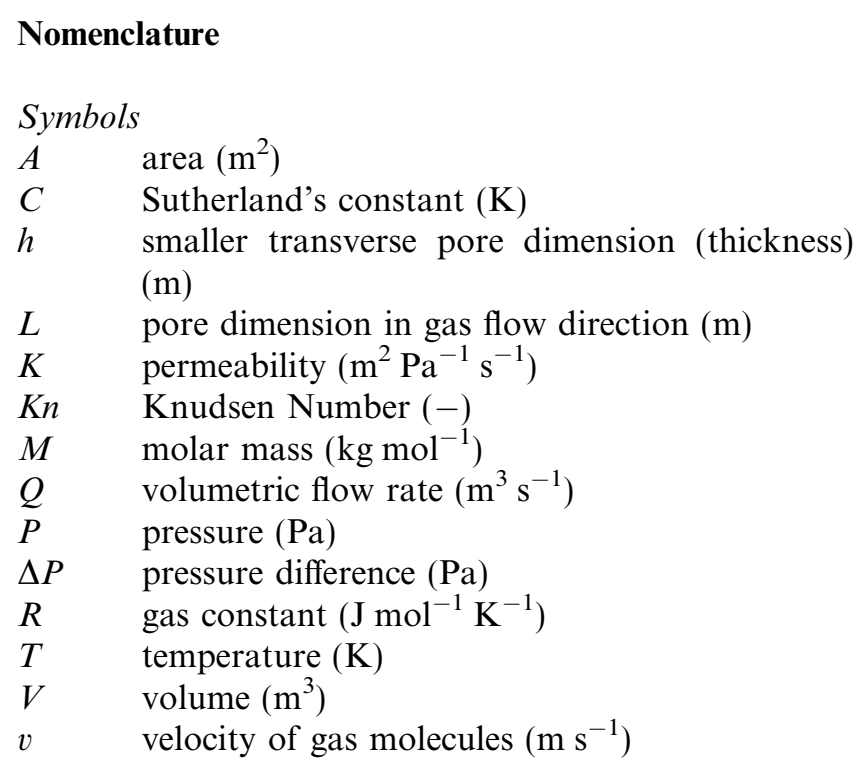

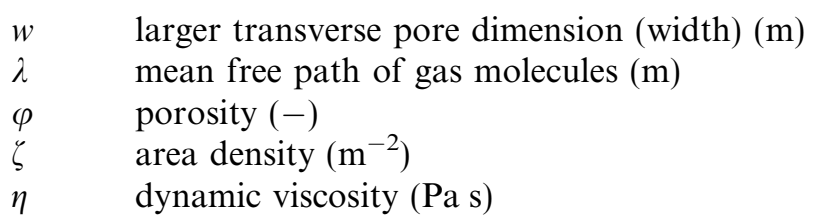

\section{Subscripts}

cr (intra-splat) microcracks

in at entry to gas flow channel

Knud Knudsen flow

Out at exit to gas flow channel

Pois Poiseuille flow

sp splat (thickness)

vo (inter-splat) voids prediction of gas permeation characteristics requires both specification of channel architecture and the solving of relatively complex advection-diffusion equations [33]. Fox and Clyne [34] presented a simple percolation-based approach, in which the microcracks within splats represented the rate-controlling channels for gas flow. They found that this gave fairly good agreement with their measured permeabilities, but could not be used to account for the details of their experimental results. There have been a few other attempts $[35,36]$ to simulate fluid flow through structures representative of sprayed microstructures, but in general there are no tools currently available which allow reliable predictions to be made of the gas permeability, from measured or estimated pore architecture parameters.

Part of the reason for this is that sprayed coatings tend to exhibit relatively complex pore architectures, which are on a fine scale and are sensitive to the spraying conditions [37] and to subsequent heat treatment. However, recent progress in the use of techniques such as small-angle neutron scattering $[38,39]$ and mercury intrusion porosimetry [39-41] now allows improved, and more quantitative, characterization of the pore structure in these materials. In the present work, a geometric representation of the pore and crack architecture, which is similar to one previously employed by the present authors [29] for modelling of thermal conduction in these coatings, is used to develop a new model for prediction of their gas permeability, using measured pore architecture characteristics as input data.

\section{Experimental procedures}

\subsection{Production and examination of plasma-sprayed coatings}

Coatings were produced by atmospheric plasma spraying of $\mathrm{ZrO}_{2}-7.5 \mathrm{~mol} . \% \mathrm{Y}_{2} \mathrm{O}_{3}$ powder. This was carried out using a Plasma Technik VPS facility with an F4 gun. The arc current was $650 \mathrm{~A}$, plasma power $\sim 36 \mathrm{~kW}$, stand-off distance $100 \mathrm{~mm}$, plasma gas flow rates $501 \mathrm{~min}^{-1} \mathrm{Ar}$, $41 \mathrm{~min}^{-1} \mathrm{H}_{2}$, and the powder feed flow rate $2.51 \mathrm{~min}^{-1}$ Ar. Mild steel substrates were used. When free-standing coatings were required, they were separated from the substrates by immersion in concentrated hydrochloric acid at $60{ }^{\circ} \mathrm{C}$ for $30 \mathrm{~min}$. Further details of the procedures employed are available in the papers of Fox and Clyne $[8,34,42]$.

Microstructural examination was carried out using a FEG-SEM. Two types of coating specimen were examined - free surfaces (in-plane) and fracture surfaces (transverse sections). An example of the latter is shown in Fig. 1. Thermal spray coatings are generated by molten droplets

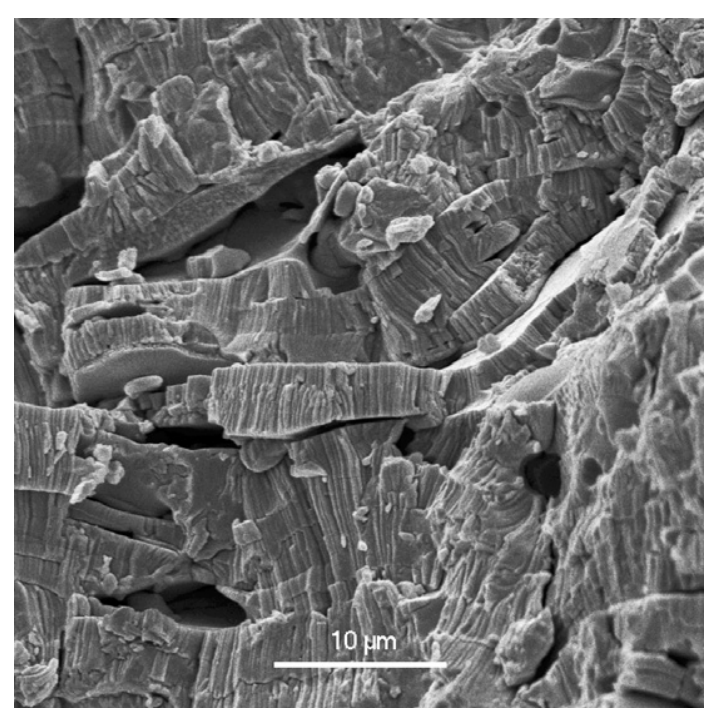

Fig. 1. SEM micrograph of the fracture surface of a yttria-stabilized zirconia (YSZ) coating produced by atmospheric plasma spraying (APS). 
striking the substrate and spreading to form pancakeshaped splats, typically with a thickness, $L_{\mathrm{sp}} \sim 1-3 \mu \mathrm{m}$. It can be seen that, in general, there is relatively poor bonding between overlapping splats. Some bridging areas between asperities on the contacting surfaces are inevitably present, but there are often relatively large areas of poor contact. Depending on the spraying conditions [37], the average gap between overlapping splats $\left(h_{\mathrm{vo}}\right)$ is usually in the range of $\sim 50-200 \mathrm{~nm}$. Porosity of this type has been reported $[38,39]$ to constitute approximately one-third of the total pore volume.

\subsection{Single splat production and examination}

In addition to conventional coating production, single splat spraying was carried out, in order to give further information about splat dimensions and microcracks, although it is recognized that single, isolated splats form and cool under slightly different conditions from those experienced by splats during coating production. Spraying was performed onto a rotating drum covered by stainless steel foil. Full details of this procedure ("The Linescan Test") are given by Roberts and Clyne [43]. Free surface micrographs are shown in Fig. 2. Some splat fragmentation
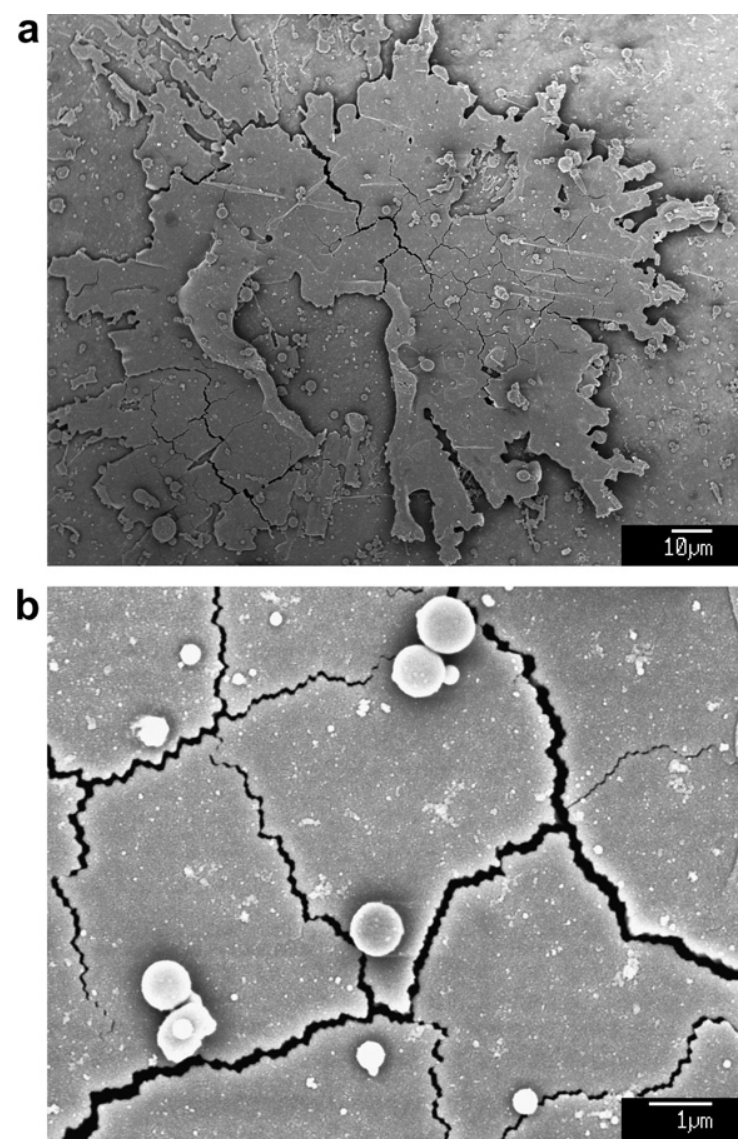

Fig. 2. SEM micrographs of free surfaces of a single splat of YSZ, produced by APS, at (a) low and (b) high magnification. is apparent, which does not always occur during coating production.

However, the main interest is in the network of microcracks visible in Fig. 2b, which are almost inevitably present (in ceramic coatings). They arise from the constraint imposed by contact with the (relatively cold) underlying substrate (or splats) on the thermal contraction that occurs during splat quenching. The nature of this process, and the associated residual stress generation, has been extensively studied [44-46]. These microcracks normally extend through the complete thickness of the splat. The crackopening displacements of intra-splat microcracks $\left(h_{\mathrm{cr}}\right)$ often cover a relatively wide range (see Fig. 2b) - values from about $300 \mathrm{~nm}$ down to a few tens of nanometres are commonly observed, while the in-plane spacing between them $\left(L_{\mathrm{vo}}\right)$ might typically be of the order of $5 \mu \mathrm{m}$. These cracks are also reported [38,39] to constitute approximately one-third of the total porosity. The remaining third is in the form of relatively coarse dispersed globular pores, typically with dimensions of the order of a few microns.

Height profiles of single splats were obtained using a Wyko RS-2 Interferometric Surface Profilometer, with lateral and depth resolutions of $\sim 1$ and $\sim 5 \mathrm{~nm}$, respectively. A typical profile is shown in Fig. 3. About 10 splats were studied in this way and the average splat thickness $\left(L_{\mathrm{sp}}\right)$ was found to be about $2.5 \mu \mathrm{m}$, which is broadly consistent with SEM observations on fracture surfaces.

\subsection{Heat treatment}

Heat treatment can substantially modify these microstructures, particularly at relatively high temperatures (> 1000-1200 ${ }^{\circ} \mathrm{C}$ for zirconia coatings). For example, sintering phenomena can take place which heal microcracks see Fig. 4. This effect has been confirmed by SANS experiments [38], which suggest a significant drop in the

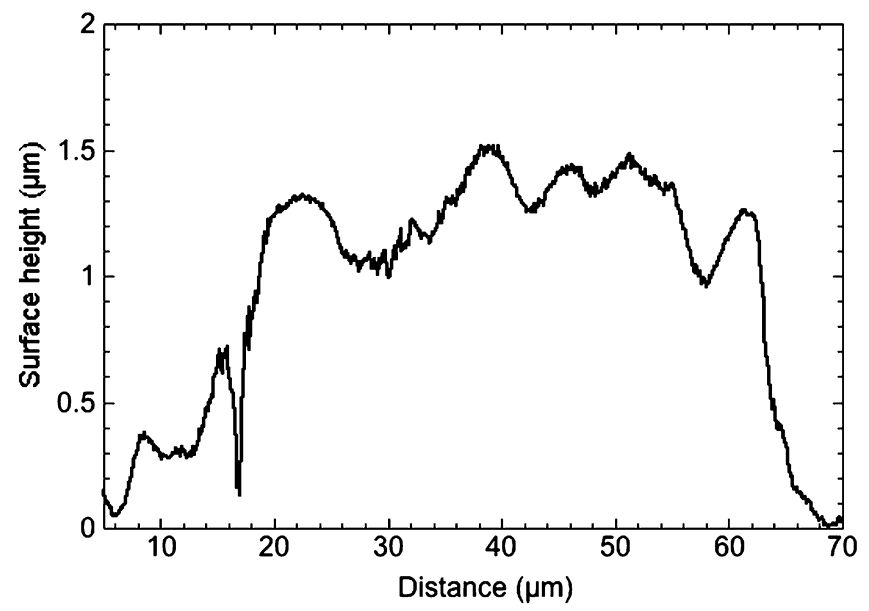

Fig. 3. Profilometry plot showing the thickness distribution across the diameter of a single YSZ splat. 


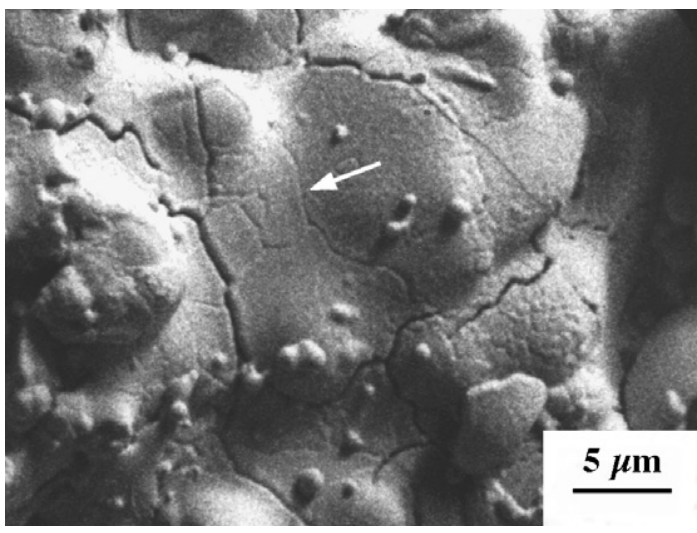

Fig. 4. SEM micrograph of the free surface of a YSZ coating produced by APS, after a heat treatment of $10 \mathrm{~h}$ at $1400{ }^{\circ} \mathrm{C}$. The arrow indicates a microcrack which has been healed by sintering during the heat treatment.

porosity contributed by microcracks, from about 4 to $1.5 \%$, after $1 \mathrm{~h}$ at $1400{ }^{\circ} \mathrm{C}$ (while the overall porosity level of $\sim 14 \%$ changed relatively little during this treatment [38]). Sintering also affects the inter-splat porosity. This is illustrated by Fig. 5. Substantial increases in the inter-splat bridge area can occur. For example, results of Allen et al. [38] indicated an increase in fractional bridge area from $20-30 \%$ to $50-60 \%$ (of the total splat contact area), after

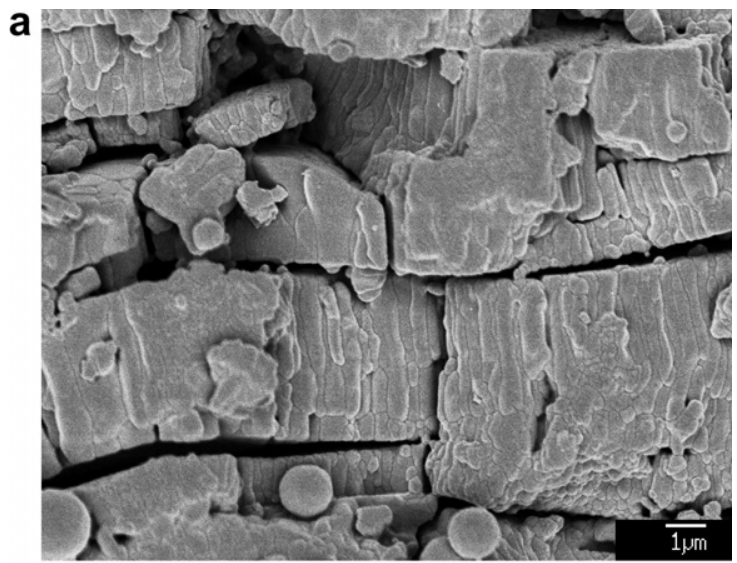

b

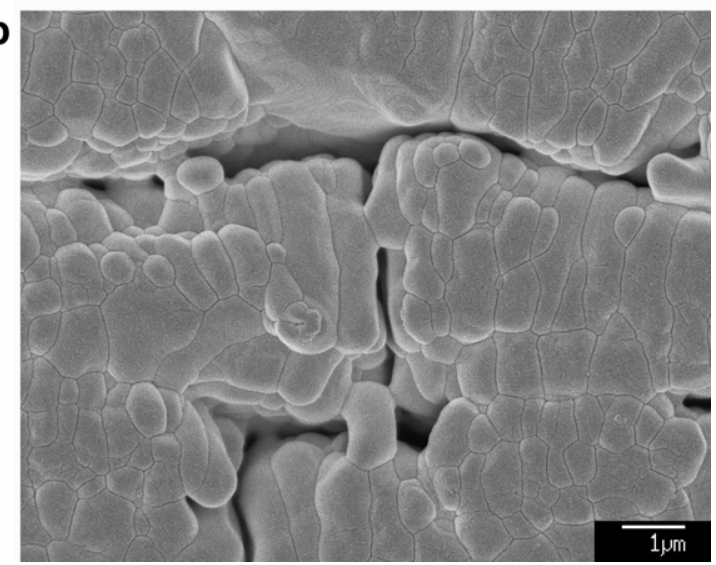

Fig. 5. SEM micrographs of fracture surfaces of a YSZ coating produced by APS, (a) as-sprayed and (b) after a heat treatment of $10 \mathrm{~h}$ at $1400^{\circ} \mathrm{C}$.
$1 \mathrm{~h}$ at $1400{ }^{\circ} \mathrm{C}$, with the corresponding porosity contribution dropping from $\sim 6$ to $\sim 4 \%$.

\subsection{Mercury intrusion porosimetry}

Mercury porosimetry was carried out using a Micromeritics Autopore IV facility, with the applied mercury pressure varying from 0 to $200 \mathrm{MPa}$. This pressure range allows detection and size analysis of inter-connected pores with dimensions in the range from around a few microns down to $7 \mathrm{~nm}$. The distribution of the incremental pore volume, as a function of the pore size $h$, is presented in Fig. 6, for both as-sprayed and heat treated $(20 \mathrm{~h}$ at $\left.1400{ }^{\circ} \mathrm{C}\right) \mathrm{YSZ}$ coatings. It can be seen that small pores $(\sim 10-50 \mathrm{~nm})$ largely disappear during this heat treatment. It is difficult to assign the ranges of $h$ in Fig. 6 corresponding to intra-splat cracks and inter-splat voids. SEM examination (Figs. 1, 2 and 5) reveals that the smallest dimensions of both cracks and inter-splat voids cover almost the whole range up to about $0.5 \mu \mathrm{m}$. SANS measurements $[38,39]$ suggest that the average value of $h_{\text {cr }}$ (microcracks) is about half that of $h_{\mathrm{vo}}$ (voids), although this may not be very reliable or universal.

\subsection{Measurement of gas permeability}

Permeability data are taken from the work of Fox and Clyne $[8,34,42]$, where full experimental details are given. These measurements were made on detached coatings in the form of thin disks. Disks of sprayed zirconia were cut and mounted onto a zirconia or alumina tube, using a soda-lime-silica sealant. Sealant curing was carried out by applying gentle pressure while heating the tube to $820^{\circ} \mathrm{C}$ for $5 \mathrm{~min}$.

Hydrogen, oxygen or, nitrogen were passed through the specimens, with a mass flow controller being used to gen-

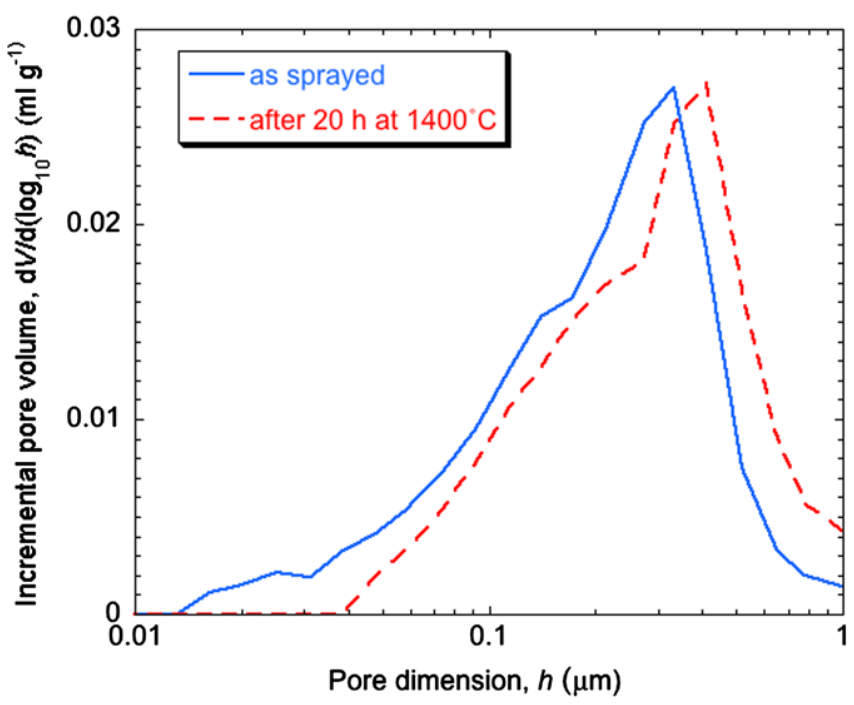

Fig. 6. Mercury porosiometry data, showing the incremental pore volume as a function of pore size, for as-sprayed and heat-treated YSZ coatings. 
erate a constant gas flow rate. After a steady state had been reached, the pressure drop across the specimens was measured with a digital manometer. Measurements were carried out over a range of temperature, from 100 to $600{ }^{\circ} \mathrm{C}$. Several measurements were made for each sample, at different flow rates. The flow rate was found to be approximately proportional to the pressure drop across the sample. Therefore the permeability was calculated using D'Arcy's law.

\section{Modelling of gas permeation}

\subsection{Geometrical representation of pore structure and gas flow routes}

Comparisons [39] between porosity levels obtained by mercury porosimetry and by Archimedean densitometry suggest that much of the porosity in these coatings is inter-connected and this is supported by various microstructural observations. In the current treatment, the large globular pores are ignored, since they clearly offer little resistance to gas flow. It is assumed that gas flows through one splat via through-thickness microcracks and then passes through inter-splat void space until it reaches a nearby microcrack in the underlying splat, when it passes through that. This is illustrated in Fig. 7.
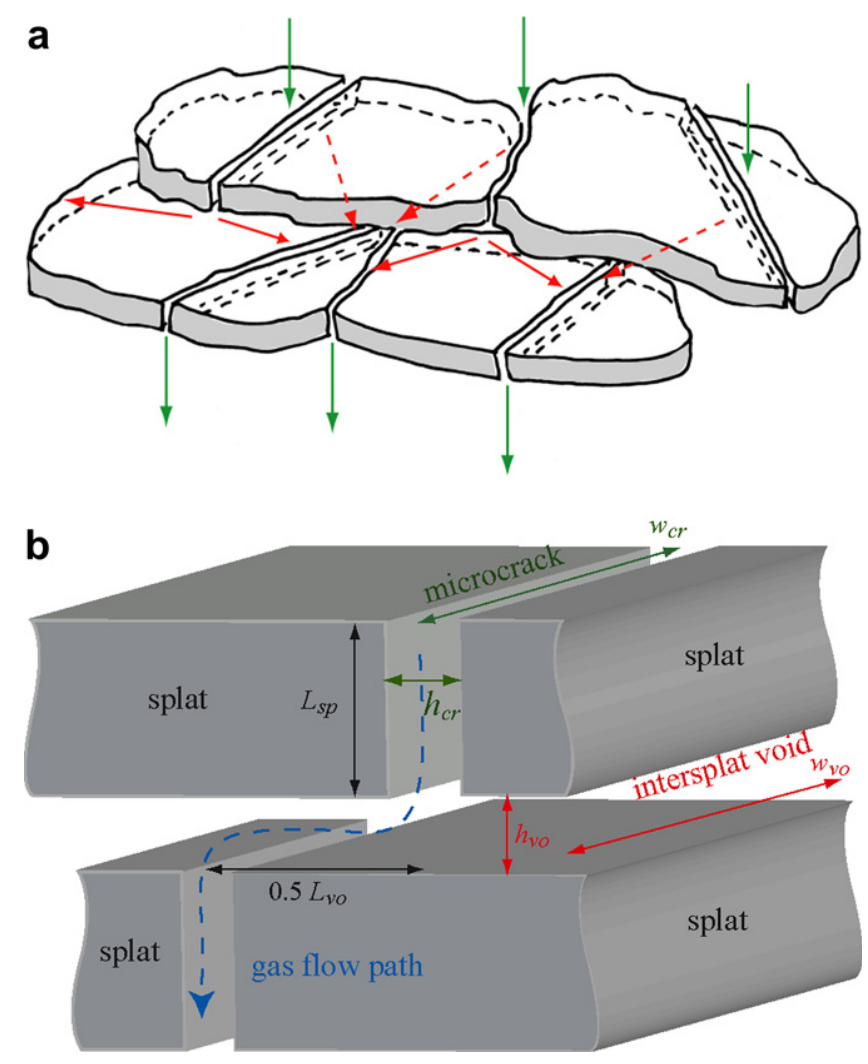

Fig. 7. Geometrical representation of gas flow paths, showing (a) perspective view of a splat assembly and (b) a section through a pair of overlapping splats.
The flow length through the microcracks is the splat thickness, $L_{\mathrm{sp}}$. The crack width, $w_{\mathrm{cr}}$, is usually much greater than $L_{\mathrm{sp}}$. It is assumed that the inter-splat porosity is evenly distributed over the inter-splat contact area. In the as-sprayed state, the contact bridge area has been reported $[38,47]$ to be about $20-30 \%$. Neglecting any effects of the range in microcrack opening displacement, gas will tend to flow towards the nearest microcrack in the underlying splat. On average, the inter-crack separation, $L_{\mathrm{vo}}$, will be given by the inverse square root of the area density of microcracks. As a first approximation, it is assumed that the gas flow distance between microcracks will be about $L_{\mathrm{vo}} / 2$. From inspection of micrographs, it is observed that this distance is about $2 \mu \mathrm{m}$ for as-sprayed coatings, increasing to perhaps $10 \mu \mathrm{m}$ after a substantial heat treatment and the associated crack healing. Of course, these figures are very approximate.

\subsection{Model specification}

\subsubsection{Gas flow through a single channel}

The symbolism used is listed in the Nomenclature. The volumetric flow rate is a function both of the geometry of the channel and of certain gas properties, especially the Knudsen number [48], given by

$K n=\frac{\lambda}{h}$

where $\lambda$ is the mean free path of the gas molecules (dependent on temperature and pressure) and $h$ is a characteristic dimension of the channel (distance between two plane walls in the present case). For the ranges of $T, P$ and channel thickness of interest here, $K n \sim 0.1-10$. In this case, the net flux is given by $[49,50]$

$Q=\frac{K n}{K n+1} Q_{\text {Knud }}+\frac{1}{K n+1} Q_{\text {Pois }}$

This flux therefore approaches those corresponding to the limiting cases of molecular (Knudsen) flow, $Q_{\mathrm{Knud}}$, and Poiseuille flow, $Q_{\text {Pois }}$, as $K n$ becomes large and small, respectively, compared to unity. The dependence of these limiting flow rates on channel dimensions and gas properties is given by [48-50]

$Q_{\mathrm{Knud}}=\frac{h^{2} w}{L} \sqrt{\frac{\pi R T}{2 M}} \frac{\Delta P}{P_{\mathrm{in}}}$

$Q_{\text {Pois }}=\frac{h^{3} w}{12 \eta} \frac{\Delta P}{L}$

in which $h, w$, and $L$ are channel dimensions, $P$ is the pressure ( $\left.\Delta P=P_{\text {in }}-P_{\text {out }}\right), T$ is the absolute temperature, $M$ is the molecular mass, and $\eta$ is the (dynamic) viscosity. Mean free path and viscosity of the gas are functions of $T$ and $P$ [48]. The viscosity can be evaluated using Sutherland's approximation

$\eta=\eta_{0}\left(\frac{0.555 T_{0}+C}{0.555 T+C}\right)\left(\frac{T}{T_{0}}\right)^{3 / 2}$ 
where $T_{0}$ is a reference temperature, $\eta_{0}$ is the viscosity at $T_{0}$ and $C$ is Sutherland's constant. The mean free path is obtained from the Maxwell-Boltzmann velocity distribution [48]

$\lambda=\frac{32 R T \eta}{5 \pi M P\langle v\rangle}$

in which the average molecular velocity is given by

$\langle v\rangle=\left(\frac{8 R T}{\pi M}\right)^{1 / 2}$

Values used for the parameters in Eqs. (5) and (6) are given in Table 1 and the calculated mean free paths are plotted in Fig. 8 for three different gases. It can be seen that the mean free path for cases of interest is likely to be of a similar order of magnitude to the channel thickness, so that use of Eq. (2) to estimate the gas flux is justified.

\subsubsection{Gas flow through intra-splat microcracks}

Gas flow through individual channels is assumed independent of flows through neighbouring channels. The total volumetric flow $Q_{\text {tot }}$, through area $A$, is thus obtained by summing the flow rates through individual channels

$Q_{\mathrm{tot}}=\sum_{\text {area } A} Q_{\mathrm{cr}}$

If all channels are identical, so that $Q_{\mathrm{cr}}$ is single-valued, then the volumetric flow rate is proportional to this value,

Table 1

Gas parameters for viscosity calculations [51]

\begin{tabular}{llll}
\hline Gas & $\begin{array}{l}\text { Reference } \\
\text { temperature } T_{0}\left({ }^{\circ} \mathrm{C}\right)\end{array}$ & $\begin{array}{l}\text { Reference viscosity } \eta_{0} \\
(\mathrm{~Pa} \mathrm{~s}) \text { at } T_{0}\end{array}$ & $\begin{array}{l}\text { Sutherland's } \\
\text { constant, } \mathrm{C}\left({ }^{\circ} \mathrm{C}\right)\end{array}$ \\
\hline $\mathrm{H}_{2}$ & 293.85 & $8.76 \times 10^{-6}$ & 40.000 \\
$\mathrm{O}_{2}$ & 292.333 & $2.02 \times 10^{-5}$ & 70.556 \\
$\mathrm{~N}_{2}$ & 300.55 & $1.78 \times 10^{-5}$ & 61.667 \\
\hline
\end{tabular}

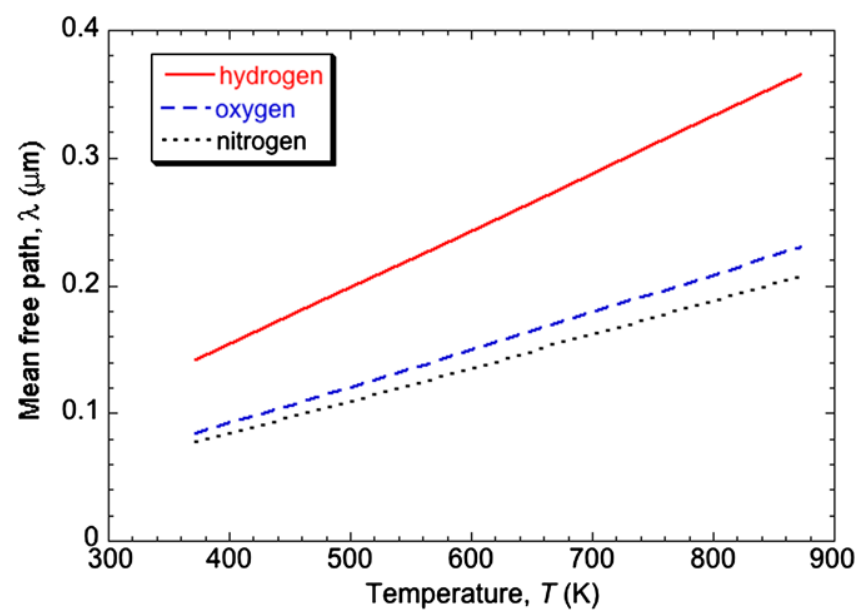

Fig. 8. Plot of mean free path as a function of temperature for three gases, obtained by substituting data in Table 1 into Eqs. (5) and (6). to the total area of the coating, $A$, and to the number of microcracks per unit area, $\zeta_{\text {cr }}$

$Q_{\mathrm{tot}}=A \zeta_{\mathrm{cr}} Q_{\mathrm{cr}}$

In the general case, the flow through each channel is a function of its dimensions and a numerical summation is necessary, involving the spatial distribution of channel sizes. For the simpler case of uniform dimensions, the crack density $\zeta_{\text {cr }}$ can be written in terms of measurable porosity parameters. In fact, the product of the crack volume $L_{\mathrm{sp}} h_{\mathrm{cr}} w_{\mathrm{cr}}$ and the number of cracks, $A \zeta_{\mathrm{cr}}$, divided by the element volume $A\left(L_{\mathrm{sp}}+h_{\mathrm{vo}}\right)$ is equal to the overall porosity contributed by cracks, $\varphi_{\mathrm{cr}}$. This relation can be written as

$\zeta_{\mathrm{cr}} L_{\mathrm{sp}} h_{\mathrm{cr}} w_{\mathrm{cr}} A=\varphi_{\mathrm{cr}}\left(L_{\mathrm{sp}}+h_{\mathrm{vo}}\right) A$

Hence,

$\zeta_{c r}=\frac{\varphi_{\mathrm{cr}}}{h_{\mathrm{cr}} w_{\mathrm{cr}}} \frac{\left(L_{\mathrm{sp}}+h_{\mathrm{vo}}\right)}{L_{\mathrm{sp}}}$

Thus, taking into account Eqs. (2)-(4), Eq. (9) reduces to

$$
\begin{aligned}
Q_{\mathrm{tot}}= & A \varphi_{\mathrm{cr}} \frac{Q_{\mathrm{cr}}}{h_{\mathrm{cr}} w_{\mathrm{cr}}} \frac{\left(L_{\mathrm{sp}}+h_{\mathrm{vo}}\right)}{L_{\mathrm{sp}}} \\
= & A \frac{\varphi_{\mathrm{cr}}}{h_{\mathrm{cr}} w_{\mathrm{cr}}} \frac{\left(L_{\mathrm{sp}}+h_{\mathrm{vo}}\right)}{L_{\mathrm{sp}}}\left(\frac{K n}{K n+1} Q_{\mathrm{mol}}+\frac{1}{K n+1} Q_{\text {Pois }}\right) \\
= & A \frac{\Delta P_{\mathrm{sp}}}{L_{\mathrm{sp}}} \frac{\left(L_{\mathrm{sp}}+h_{\mathrm{vo}}\right)}{L_{\mathrm{sp}}} \varphi_{\mathrm{cr}} \\
& \times\left(\frac{\lambda h_{\mathrm{cr}}}{\lambda+h_{\mathrm{cr}}} \sqrt{\frac{\pi R T}{2 M}} \frac{1}{P_{\mathrm{in}}}+\frac{1}{\lambda+h_{\mathrm{cr}}} \frac{h_{\mathrm{cr}}^{3}}{12 \eta}\right) \\
\equiv & A\left(L_{\mathrm{sp}}+h_{\mathrm{vo}}\right) \frac{\Delta P_{\mathrm{sp}}}{L_{\mathrm{sp}}^{2}} K_{\mathrm{cr}}
\end{aligned}
$$

with the permeability of microcracks therefore being given by

$K_{\mathrm{cr}}=\varphi_{\mathrm{cr}}\left(\frac{\lambda h_{\mathrm{cr}}}{\lambda+h_{\mathrm{cr}}} \sqrt{\frac{\pi R T}{2 M}} \frac{1}{P_{\mathrm{in}}}+\frac{1}{\lambda+h_{\mathrm{cr}}} \frac{h_{\mathrm{cr}}^{3}}{12 \eta}\right)$

In most cases, the assumption about identical channels is unlikely to introduce large errors and $h_{\mathrm{cr}}$ in Eq. (12) could be replaced by some average microcrack dimension $\left\langle h_{\mathrm{cr}}\right\rangle$, obtained experimentally.

\subsubsection{Gas flow through inter-splat voids}

Gas flow through inter-splat void space can be treated in a similar way to that through the microcracks. The number of voids in a slab with thickness $\left(L_{\mathrm{sp}}+h_{\mathrm{vo}}\right)$, per area $A$, can be expressed as $A \zeta_{\text {vo }}$, where $\zeta_{\text {vo }}$ is the number of voids per unit area. The volume of a single void $0.5 L_{\mathrm{vo}} h_{\mathrm{vo}} w_{\mathrm{vo}}$ and the total porosity of voids $\varphi_{\mathrm{vo}}$ are related by

$A \zeta_{\mathrm{vo}}\left(0.5 L_{\mathrm{vo}}\right) h_{\mathrm{vo}} w_{\mathrm{vo}}=\varphi_{\mathrm{vo}}\left(L_{\mathrm{sp}}+h_{\mathrm{vo}}\right) A$ 
with the flow rate given by

$$
\begin{aligned}
Q_{\mathrm{tot}} & =\sum_{\operatorname{area} A} Q_{\mathrm{vo}}=A \zeta_{\mathrm{vo}} Q_{\mathrm{vo}} \\
& =A \varphi_{\mathrm{vo}}\left(\frac{K n}{K n+1} Q_{\mathrm{mol}}+\frac{1}{K n+1} Q_{\mathrm{Pois}}\right) \frac{2\left(L_{\mathrm{sp}}+h_{\mathrm{vo}}\right)}{L_{\mathrm{vo}} h_{\mathrm{vo}} w_{\mathrm{vo}}}
\end{aligned}
$$

Introducing the permeability of individual inter-splat voids $K_{\mathrm{vo}}$, Eq. (14) can be written

$Q_{\mathrm{tot}}=A \frac{2\left(L_{\mathrm{sp}}+h_{\mathrm{vo}}\right)}{L_{\mathrm{vo}}} \frac{\Delta P_{\mathrm{vo}}}{0.5 L_{\mathrm{vo}}} K_{\mathrm{vo}}$

Substituting expressions for molecular and Poiseuille flows (Eqs. (3) and (4)) into Eq. (14) gives an expression for the permeability of individual inter-splat voids.

$K_{\mathrm{vo}}=\varphi_{\mathrm{vo}}\left(\frac{\lambda h_{\mathrm{vo}}}{\lambda+h_{\mathrm{vo}}} \sqrt{\frac{\pi R T}{2 M}} \frac{1}{P_{\mathrm{in}}}+\frac{1}{\lambda+h_{\mathrm{vo}}} \frac{h_{\mathrm{vo}}^{3}}{12 \eta}\right)$.

The value of $K_{\mathrm{vo}}$ can thus be obtained from the void content and the void thickness, in the same way as for $K_{\mathrm{cr}}$.

\subsubsection{Overall permeability of the coating}

The net permeability $K_{\text {tot }}$ of a unit cell, with height $L_{\mathrm{sp}}+h_{\mathrm{vo}}$ and area $A$, can be expressed in terms of the overall volumetric flow rate through the cell and the pressure drop across it.

$Q_{\mathrm{tot}}=A K_{\mathrm{tot}} \frac{\Delta P_{\mathrm{tot}}}{\left(L_{\mathrm{sp}}+h_{\mathrm{vo}}\right)}$

The overall flow rate through microcracks and inter-splat voids must be the same, so that

$$
\begin{aligned}
Q_{\mathrm{tot}} & =A K_{\mathrm{tot}} \frac{\Delta P_{\mathrm{tot}}}{\left(L_{\mathrm{sp}}+h_{\mathrm{vo}}\right)} \\
& =A K_{\mathrm{cr}}\left(L_{\mathrm{sp}}+h_{\mathrm{vo}}\right) \frac{\Delta P_{\mathrm{sp}}}{L_{\mathrm{sp}}^{2}} \\
& =A \frac{4\left(L_{\mathrm{sp}}+h_{\mathrm{vo}}\right)^{2}}{L_{\mathrm{vo}}^{2}} \frac{\Delta P_{\mathrm{vo}}}{\left(L_{\mathrm{sp}}+h_{\mathrm{vo}}\right)} K_{\mathrm{vo}}
\end{aligned}
$$

By substituting in this equation for the total pressure drop, which is given by

$\Delta P_{\text {tot }}=\Delta P_{\mathrm{sp}}+\Delta P_{\mathrm{vo}}$

the overall permeability can be expressed in the form

$K_{\mathrm{tot}}=\left(\frac{L_{\mathrm{sp}}+h_{\mathrm{vo}}}{L_{\mathrm{sp}}}\right)^{2} K_{\mathrm{cr}}\left(1+\frac{L_{\mathrm{vo}}^{2} K_{\mathrm{cr}}}{4 L_{\mathrm{sp}}^{2} K_{\mathrm{vo}}}\right)^{-1}$ and, since $h_{\mathrm{vo}}<<L_{\mathrm{sp}}$, this can be written

$K_{\mathrm{tot}} \approx K_{\mathrm{cr}}\left(1+\frac{L_{\mathrm{vo}}^{2} K_{\mathrm{cr}}}{4 L_{\mathrm{sp}}^{2} K_{\mathrm{vo}}}\right)^{-1}$

The value of $K_{\text {tot }}$ can thus be obtained from the permeabilities calculated in Sections 3.2.2 and 3.2.3, plus the pore architecture parameters $L_{\mathrm{vo}}$ and $L_{\mathrm{sp}}$.

\section{Model predictions and comparison with experimental data}

\subsection{As-sprayed coatings}

A comparison is shown in Fig. 9 between measured and predicted permeabilities of as-sprayed YSZ coatings, for three gases, over a range of temperature. The predictions were obtained using Eqs. (12), (16), and (20), assuming uniform dimensions of cracks and voids. The gas property data used are shown in Table 1 and the pore levels and dimensions employed were those presented in Table 2. The values of $h_{\mathrm{cr}}$ and $h_{\mathrm{vo}}$ were estimated from the pore size distribution shown in Fig. 6 and data from SANS experiments [38,39], which suggest that average $h_{\mathrm{cr}}$ values are

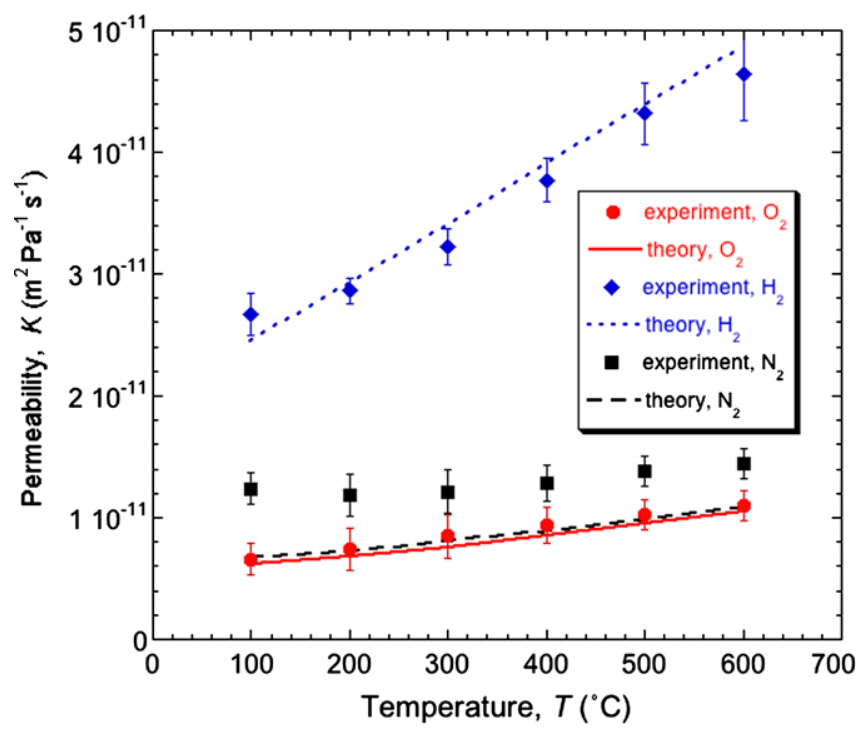

\begin{tabular}{|c|c|c|c|c|c|c|c|c|}
\hline & \multicolumn{5}{|c|}{ Pore dimensions $(\mu \mathrm{m})$} & \multicolumn{3}{|c|}{ Porosity (\%) } \\
\hline & \multicolumn{4}{|c|}{ Intra-splat microcracks } & \multirow{2}{*}{$\frac{\text { Inter-splat voids }}{\text { Thickness } h_{\mathrm{vo}}}$} & \multirow{2}{*}{$\frac{\text { Cracks }}{\varphi_{\mathrm{cr}}^{\text {tot }}}$} & \multirow{2}{*}{$\frac{\text { Voids }}{\varphi_{\mathrm{vo}}^{\text {tot }}}$} & \multirow[t]{2}{*}{ Globular } \\
\hline & Thickness $h_{\mathrm{cr}}$ & Width $w_{\text {cr }}$ & Length $L_{\mathrm{sp}}$ & Separation $L_{\mathrm{vo}}$ & & & & \\
\hline $1 \mathrm{~h} @ 1400^{\circ} \mathrm{C}$ & 0.25 & 1.69 & 2.5 & 7.5 & 0.35 & 1.5 & 1.5 & 4 \\
\hline $20 \mathrm{~h} @ 1400^{\circ} \mathrm{C}$ & 0.3 & 1.67 & 2.5 & 10 & 0.4 & 1 & 1 & 4 \\
\hline
\end{tabular}

Fig. 9. Predicted and measured permeabilities of as-sprayed YSZ coatings, for three gases, as a function of temperature.

Table 2

Pore architecture parameters used in the model 
$\sim 50-75 \%$ of average $h_{\mathrm{vo}}$ values, and that porosity levels of intra-splat microcracks and inter-splat voids are similar. Agreement between predictions and experiment is encouraging, considering the crude nature of the model and input data.

Fig. 10 shows the effect of pore architecture parameters on predicted permeability values. The microstructural parameters used in these plots have been varied in a consistent way - for example, changes in the microcrack thickness, at a fixed porosity level, require corresponding changes in microcrack separation. Assuming random orientation of intra-splat microcracks, the relationship may be written

$\varphi_{\mathrm{cr}}=\frac{2 w_{\mathrm{cr}} h_{\mathrm{cr}}}{L_{\mathrm{vo}}^{2}}$

Table 3 shows how the parameters have been varied in constructing Fig. 10. It can be seen that the predictions are sensitive to both microcrack (Fig. 10a) and inter-splat void parameters (Fig. 10b). The main resistance to gas flow is presented by long pores with small flank separation. For plasma-sprayed coatings, microcracks and inter-splat voids have broadly similar dimensions and their contributions to the gas permeability are similar in magnitude. It is worth noting that microcrack healing (disappearance) leads to increased flow distances along inter-splat void channels.

It can be seen in Fig. 10 that the permeability is approximately linearly dependent on several architectural parameters: the level of microcrack porosity, the channel length, and the thickness (flank separation) of microcracks. The former effect is intuitive, while the latter follows from Eq. (14), since Knudsen flow predominates in the microcracks (see below). Simultaneous variation of two parameters (e.g., porosity $\varphi$ and flank separation $h$ ) tends to give a net effect which is simply the sum of the individual effects, as can be seen in Fig. 10a.

The mean free path increases with increasing temperature. In fact, $\lambda$ will often be significantly greater than the shortest pore dimension (see Fig. 8), so that Knudsen flow is often expected to dominate at typical service tempera-
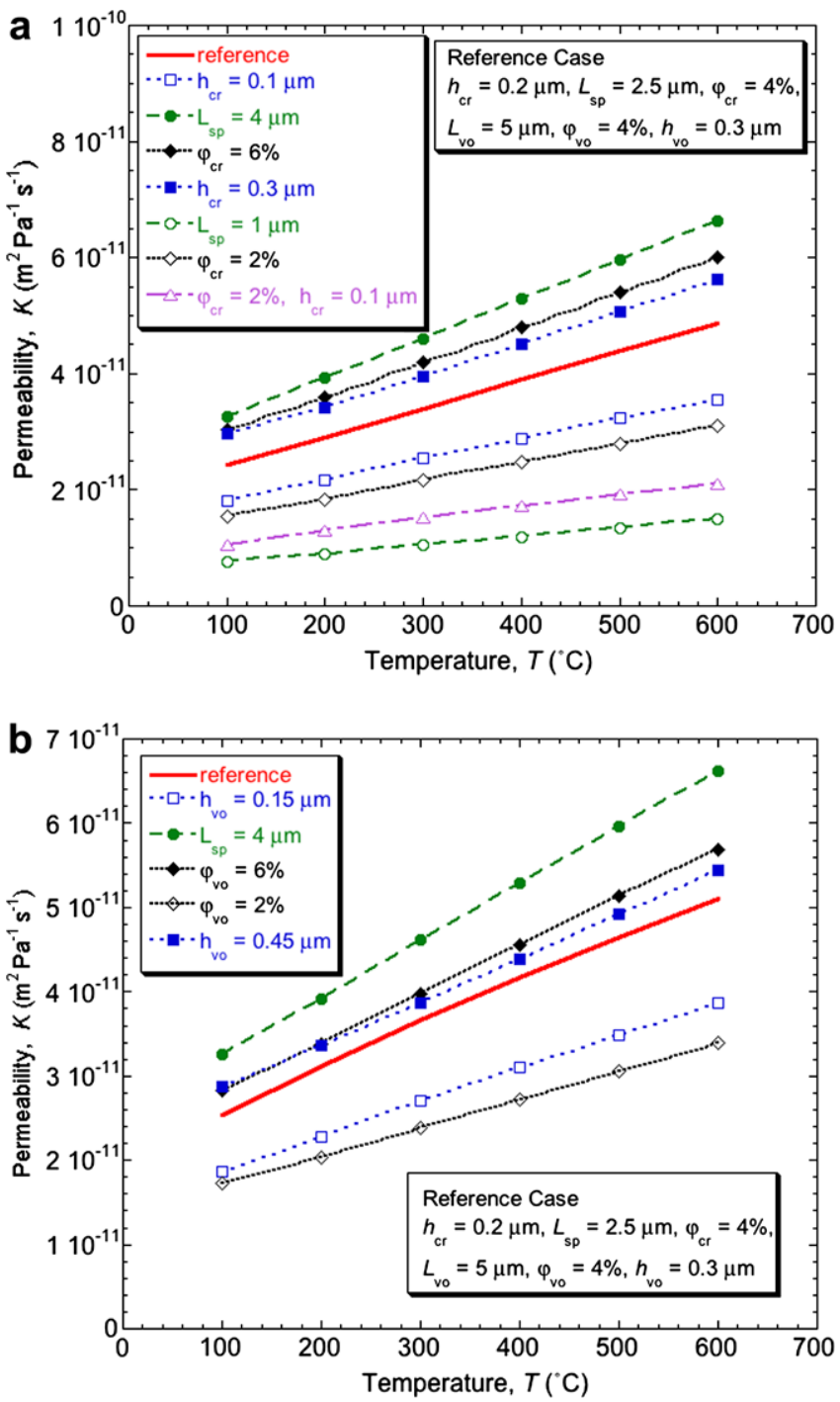

Fig. 10. Predicted permeability for hydrogen, as a function of temperature, for as-sprayed YSZ coatings, showing the sensitivity to variations in (a) microcrack parameters and (b) inter-splat void parameters.

tures (e.g., $\sim 1200^{\circ} \mathrm{C}$ for $\mathrm{TBCs}$ ). This means that the gas viscosity does not really affect the permeation characteristics. On the other hand, for such high $\lambda$ values, the

Table 3

Pore architecture parameters used for sensitivity analysis

\begin{tabular}{|c|c|c|c|c|c|c|c|c|}
\hline \multirow[b]{3}{*}{ Parameters to vary } & \multicolumn{5}{|c|}{ Pore dimensions $(\mu \mathrm{m})$} & \multicolumn{3}{|c|}{ Porosity (\%) } \\
\hline & \multicolumn{4}{|c|}{ Intra-splat microcracks } & \multirow{2}{*}{$\begin{array}{l}\text { Inter-splat voids } \\
\text { Thickness } h_{\mathrm{vo}}\end{array}$} & \multirow{2}{*}{$\frac{\text { Cracks }}{\varphi_{\mathrm{cr}}^{\text {tot }}}$} & \multirow{2}{*}{$\frac{\text { Voids }}{\varphi_{\text {vo }}^{\text {tot }}}$} & \multirow[t]{2}{*}{ Globular } \\
\hline & Thickness $h_{\mathrm{cr}}$ & Width $w_{\text {cr }}$ & Length $L_{\mathrm{sp}}$ & Separation $L_{\mathrm{vo}}$ & & & & \\
\hline$h_{\mathrm{cr}}, w_{\mathrm{cr}}$ & 0.3 & 1.67 & 2.5 & 5 & 0.3 & 4 & 4 & 4 \\
\hline$\varphi_{\mathrm{cr}}^{\mathrm{tot}} w_{\mathrm{cr}}$ & 0.2 & 1.25 & 2.5 & 5 & 0.3 & 2 & 4 & 4 \\
\hline$\varphi_{\mathrm{cr}}^{\mathrm{tot}} w_{\mathrm{cr}}$ & 0.2 & 3.75 & 2.5 & 5 & 0.3 & 6 & 4 & 4 \\
\hline$\varphi_{\mathrm{vo}}^{\mathrm{tot}}$ & 0.2 & 2.5 & 2.5 & 5 & 0.3 & 4 & 2 & 4 \\
\hline$\varphi_{\mathrm{vo}}^{\text {tot }}$ & 0.2 & 2.5 & 2.5 & 5 & 0.3 & 4 & 6 & 4 \\
\hline$h_{\mathrm{vo}}$ & 0.2 & 2.5 & 2.5 & 5 & 0.15 & 4 & 4 & 4 \\
\hline$h_{\mathrm{vo}}$ & 0.2 & 2.5 & 2.5 & 5 & 0.45 & 4 & 4 & 4 \\
\hline
\end{tabular}




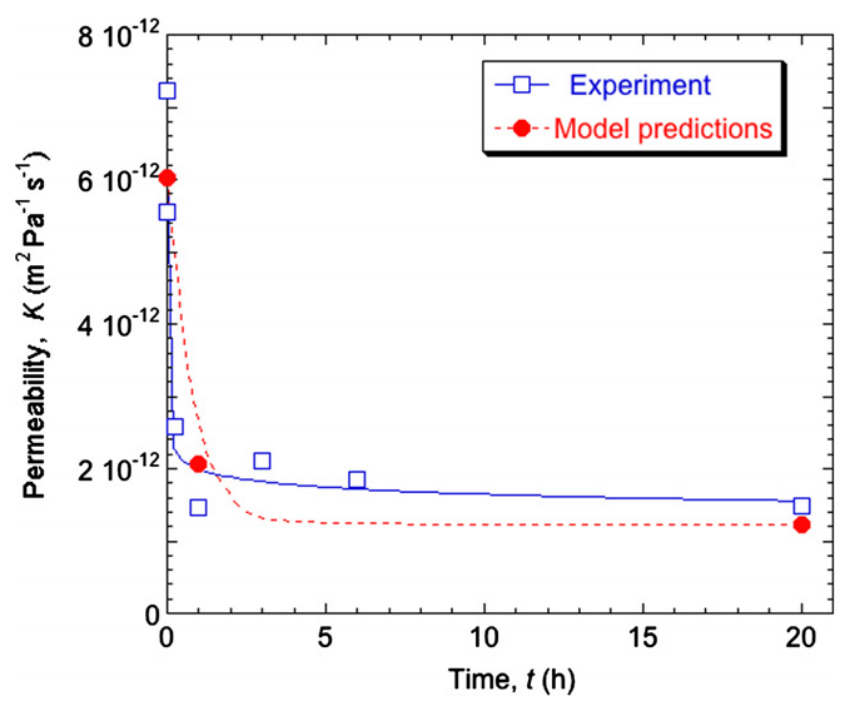

Fig. 11. Predicted and measured permeabilities of YSZ coatings for oxygen, as a function of heat treatment time at $1400^{\circ} \mathrm{C}$.

permeability $K_{\mathrm{cr}}$ is almost independent of $\lambda$ (see Eq. (12), for $\lambda>>h_{\mathrm{cr}}$ ) and the square root law is a good approximation. In this case, the permeability is a function only of the pore dimensions and the molecular mass of the gas.

\subsection{Effect of heat treatment}

Under service conditions (high $T$ ), these coatings are prone to microstructural change, as a result of sintering phenomena. For example, microcracks tend to become healed (see Fig. 4). This effect has been confirmed by SANS experiments [38], as well as by microscopy and MIP studies. The SANS work suggests a drop in the microcrack porosity level from $4 \%$ to $1.5 \%$, after $1 \mathrm{~h}$ at $1400{ }^{\circ} \mathrm{C}$, with a further drop to $1 \%$ after $20 \mathrm{~h}$, which is consistent with the MIP results presented here. It was also deduced [38] that the value of $h_{\mathrm{cr}}$ rose from 200 to $300 \mathrm{~nm}$ during these treatments. These and other input data for the model are shown in Table 2. Of course, these numbers are inevitably rather approximate. Nevertheless, it can be seen in Fig. 11 that both the measured permeability and the value predicted on the basis of these estimated pore architecture data tend to fall quite sharply with heat treatment time (at this admittedly rather high temperature of $1400^{\circ} \mathrm{C}$ ). The agreement is again encouraging, although obviously the estimates of the architecture data are rather approximate and these values are all assumed to be uniform.

\section{Conclusions}

The following conclusions can be drawn from this work.

(a) A model has been presented for prediction of the permeability of ceramic coatings produced by thermal spraying. It is based on pore architecture in which gas flow takes place sequentially through void space between overlapping splats and through-thickness intra-splat microcracks. The nature of the flow is dependent on the molecular mean free path, $\lambda$ which may be comparable in magnitude with the dimensions of gas flow channels.

(b) The predicted permeability is approximately proportional to the square root of the absolute temperature and inversely proportional to the square root of the molecular mass of the gas. Gas flow occurs primarily in the Knudsen regime ( $\lambda \sim$ channel thickness), especially at relatively high temperatures.

(c) Comparisons with experiment have been made for plasma-sprayed zirconia (thermal barrier) coatings. Good agreement is found between predicted permeability values, obtained using measured pore architecture data from previous and current work, and published experimental values, for three different gases and a range of temperature. Typical values are in the range $10^{-11}-10^{-10} \mathrm{~m}^{2} \mathrm{~Pa}^{-1} \mathrm{~s}^{-1}$. It follows that the model can be used to predict the permeability, and hence the gas flow characteristics, of coatings with this type of pore structure, provided that the relevant porosity levels and dimensions can be estimated.

(d) A parametric analysis has revealed that the predicted permeability is equally sensitive to microcrack dimensions and inter-splat void architecture.

(e) Prolonged exposure of (detached) coatings of this type to high temperature $\left(>\sim 1000{ }^{\circ} \mathrm{C}\right)$ leads to sintering and consequent microstructural changes. Previous work has shown that these are accompanied by sharp drops in permeability, as some of the gas flow channels become closed. The main features of these changes are captured in the model, using measured pore architecture data.

\section{Acknowledgements}

Funding for this study has been provided by EPSRC, through a Platform Grant, and the Gates Foundation (for SP). The authors are grateful for ongoing collaborative help from Sulzer-Metco, and particularly for useful discussions with Clive Britton, Keith Harrison, and Mitch Dorfman.

\section{References}

[1] Miller RA. J Therm Spray Technol 1997;6:35.

[2] Tamura M, Takahashi M, Ishii J, Suzuki K, Sato M, Shimomura K. J Therm Spray Technol 1999;8:68

[3] Singheiser L, Steinbrech R, Quadakkers WJ, Herzog R. Mater High Temp 2001;18:249.

[4] Langhahr PA, Oberacker R, Hoffmann MJ. J Am Cer Soc 2001;84:1301.

[5] Stover D, Pracht G, Lehmann H, Dietrich M, Doring JE, Vassen R. J Therm Spray Technol 2004;13:76.

[6] Kaga Y, Ohno Y, Tsukamoto K, Uchiyama F. Solid State Ionics 1990;40/41:1000. 
[7] Fukumoto M, Ueda T, Okane I. J Mater Sci Lett 1994;13:656.

[8] Fox AC, Clyne TW. Surf Coat Technol 2004;184:311.

[9] Suemoto T, Ishigame M. Solid State Ionics 1986;21:225.

[10] Manning PS, Sirman JD, Souza RAD, Kilner JA. Solid State Ionics 1997;100:1.

[11] Tai L, Lessing P. J Am Ceram Soc 1991;74:501.

[12] Nicoll A, Salito A. Solid State Ionics 1992;52:269.

[13] Minh NQ. J Am Ceram Soc 1993;76:563.

[14] Zievers JF, Eggerstedt P, Zievers EC. Am Ceram Soc Bull 1991;70:108.

[15] Bhave RR. Inorganic membranes synthesis, characteristics, and applications. New York: Van Nostrand Reinhold; 1991.

[16] Ohno Y, Kaga Y, Monma A, Tsukamoto K, Uchiyama F, Okuo T. Evaluation of gas permeabilities of solid oxide fuel cell components. In: Grosz F, Zegers P, Singhal S, Yamamoto O, editors. Proceedings of the second international symposium on solid oxide fuel cells, vol. 1. Athens, Greece: Commission of the European Communities; 1991. p. 455.

[17] Marumoto K, Aya S, Matsui Y. JSME Int J Series II - Fluids Eng, Heat Transfer, Power, Combustion, Thermophysical Props 1992;35:293.

[18] Siebert B, Funke C, Vassen R, Stover D. J Mater Proc Technol 1999;93:217

[19] Vogt T, Hunter BA, Thornton J. J Am Ceram Soc 2001;84:678.

[20] Vassen R, Czech N, Mallener W, Stamm W, Stoever D. Surf Coat Technol 2001;141:135.

[21] Strunz P, Schumacher G, Vassen R, Wiedenmann A. Acta Materialia 2004;52:3305.

[22] Zhang J, Desai V. Surf Coat Technol 2005;190:98.

[23] Thompson JA, Clyne TW. Acta Materialia 2001;49:1565.

[24] Tsipas SA, Golosnoy IO, Damani R, Clyne TW. J Therm Spray Technol 2004;13:370.

[25] Wakui T, Malzbender J, Steinbrech RW. Surf Coat Technol 2006;200:4995.

[26] Zhu DM, Miller RA. J Therm Spray Technol 2000;9:175.

[27] Dutton R, Wheeler R, Ravichandran KS. J Therm Spray Technol 2000;9:204.

[28] Trice RW, Su YJ, Mawdsley JR, Faber KT, De Arellano-Lopez AR, Wang H, Porter WD. J Mater Sci 2002;37:2359.

[29] Golosnoy IO, Tsipas SA, Clyne TW. J Therm Spray Technol $2005 ; 14: 205$
[30] Carman P. Flow of Gases Through Porous Media. London: Butterworth; 1956.

[31] Dullien FAL. Porous Media: Fluid Transport and Pore Structure. San Diego; London: Academic Press; 1992.

[32] Scheidegger AE. The Physics of Flow through Porous Media. Toronto: University of Toronto Press; 1974.

[33] Mason E, Malinauskas A, Evans R. J Chem Phys 1967;46:3199.

[34] Fox AC, Clyne TW. The gas permeability of plasma sprayed ceramic coatings. In: Berndt CC, editor. Thermal spray: a united forum for scientific and technological advances. Proceedings of the first united thermal spray conference Indianapolis, USA: ASM; 1998. p. 483.

[35] Uchytil P, Broz Z. J Membrane Sci 1994;97:145.

[36] Nylen P, Wigren J, Pejryd L, Hansson MO. J Therm Spray Technol 1999;8:393.

[37] Kulkarni A, Vaidya A, Goland A, Sampath S, Herman H. Mat Sci Eng A 2003;359:100.

[38] Allen AJ, Ilavsky J, Long GG, Wallace JS, Berndt CC, Herman H. Acta Materialia 2001;49:1661.

[39] Kulkarni A, Wang Z, Nakamura T, Sampath S, Goland A, Herman $\mathrm{H}$, et al. Acta Materialia 2003;51:2457.

[40] Ilavsky J, Berndt CC, Karthikeyan J. J Mater Sci 1997;32:3925.

[41] Siebert S, Funke C, Vassen R, Stover D. J Mater Proc Technol 1999:93

[42] Fox AC, Clyne TW. Oxygen transport through the zirconia top coat in thermal barrier coating systems. In: Coddet C, editor. Thermal spray: Meeting the challenges of the 21st century. Proceedings of the 15th international thermal spray conference, vol. 2. Nice, France: ASM International; 1998. p. 1589.

[43] Roberts KA, Clyne TW. Surf Coat Technol 1990;41:103.

[44] Kuroda S, Clyne TW. Thin Solid Films 1991;200:49.

[45] Kuroda S, Fukushima T, Kitahara S. J Therm Spray Technol 1995;4:75.

[46] Scardi P, Leoni M, Bertamini L. Thin Solid Films 1996;278:96.

[47] McPherson R. Surf Coat Technol 1989;39/40:173.

[48] Hirschfelder JO, Curtiss CF, Bird RB. Molecular theory of gases and liquids. New York: Wiley; 1954.

[49] Stops DW. J Phys D: Appl Phys 1970;3:685.

[50] Roberts GT. J Phys A: Gen Phys 1971;4:401.

[51] CRC. Handbook of Chemistry and Physics. Cleveland: CRC Press; 1976. p. 77. 